\title{
Extrativismo marinho e desenvolvimento sustentável na Comunidade Tradicional de Carnaubeiras (MA)
}

\author{
Maria Rodrigues Garcia \\ Universidade Estadual do Maranhão (UEMA) \\ Isaac Giribet Bernat \\ Universidade Estadual do Maranhão (UEMA)
}

Recebido: 22/09/2017 Versão revisada (entregue): 15/06/2019 Aprovado: 25/06/2019

\begin{abstract}
Resumo
Neste artigo se examina a relação da sustentabilidade dos recursos naturais com os modos de produção extrativistas marinhos desenvolvidos pela comunidade tradicional do povoado de Carnaubeiras, localizado no município de Araioses, no estado do Maranhão. Tais atividades são desenvolvidas em uma Unidade de Conservação, a Reserva Extrativista Marinha do Delta do Parnaíba. As atividades extrativistas marinhas foram analisadas à luz dos princípios da sustentabilidade, utilizando-se o método dialético e a análise qualitativa, realizada através de entrevistas semiestruturadas e observações diretas a partir de visitas a campo, tendo em vista a compreensão da totalidade dos fenômenos e uma interpretação dos acontecimentos por meio da obtenção dos dados coletados no local estudado. Os resultados evidenciaram a insustentabilidade do desenvolvimento promovido com base na sobre-exploração dos recursos naturais e da força de trabalho humano dos grupos de extrativistas marinhos. A conclusão é que a exploração desmedida, tanto da força de trabalho humano quanto da natureza, contradiz as intenções conservacionistas e coloca em xeque o modelo de conservação pré-estabelecido para a área.
\end{abstract}

Palavras-chave | Carnaubeiras; comunidades tradicionais; desenvolvimento sustentável; extrativismo marinho; força de trabalho; recursos naturais.

Código JEL | J15 Q01 Q25

Marine extractive activity and sustainable development in the traditional community of Carnaubeiras in Maranhão

\begin{abstract}
Given the current crisis of the productive system regarding the sustainability of natural resources, it brings to attention the problem related to this work. It relates to sustainability with marine extractive production methods developed by the traditional community Carnaubeiras
\end{abstract}


village in the town of Araioses-MA. These extractive activities are developed in a conservation area, the RESEX (Reserva Extrativista - "Extractive Reserve") Marinha do Delta do Parnaíba characterized by the destruction of natural resources and exploration of human labor. Therefore, an analysis of the dynamics of these marine extractive activities was conducted on the principles of sustainability, using the dialectical method and qualitative analysis on field visits through interviews and direct observations. The goal is to understand the entire phenomenon as well as the interpretation of events through the collected data in the studied site. From the analyzed data it was evidenced the existence of unsustainability of development promoted through overexploitation of natural resources as well as human workforce of extractives groups. It is concluded that the excessive exploitation of human and nature workforce contradicts the pattern of conservation predetermined in the area and the conservationist intention.

Keywords | Carnaubeiras; marine extractive activity; natural resources; sustainable development; traditional communities; workforce.

JEL-Code | J15 Q01 Q25

\section{Extractivismo marino y desarrollo sostenible en la Comunidad Tradicional de Carnaubeiras-MA}

\section{Resumen}

En este artigo se analiza la relación de la sostenibilidad de los recursos naturales con los modos de producción extractivitas marinos desarrollados por la comunidad tradicional del poblado de Carnaubeiras, ubicado en el municipio de Araioses, en el estado de Maranhão. Dichas actividades se realizan en una Unidad de Conservación, la Reserva Extractiva Marina del Delta del Parnaíba. Las actividades extractivas marinas fueron analizadas a partir de los principios de la sostenibilidad, utilizándose el método dialéctico y el análisis cualitativo realizado mediante entrevistas semiestructuradas y observaciones directas a partir de visitas al campo, con el fin de comprender la totalidad de los fenómenos así como interpretar los acontecimientos por medio de la obtención de datos recogidos en el lugar estudiado. Los resultados evidenciaron la insostenibilidad del desarrollo promovido a través de la sobreexplotación de los recursos naturales y de la fuerza de trabajo humano de los grupos extractivistas marinos. Se concluye que la explotación desmedida, tanto de la fuerza de trabajo humana como de la naturaleza, contradice las intenciones conservacionistas e amenaza el modelo de conservación preestablecido para el área.

Palabras clave | Carnaubeiras; comunidades tradicionales; desarrollo sostenible; extractivismo marino; fuerza de trabajo; recursos naturales.

Codigo JEL | J15 Q01 Q25 


\section{Introdução}

O processo de aceleração da globalização trouxe consigo a crise ambiental, forçando o surgimento de uma nova política de desenvolvimento que pudesse combatê-la nos marcos do desenvolvimento capitalista. De acordo com os formuladores do desenvolvimento sustentável, esta nova direção busca apresentar estratégias para dar continuidade aos processos produtivos de forma sustentável. Porém, apesar da consciência ecológica buscada por meio de políticas públicas, a crise ambiental segue avançando, acentuando-se de forma bastante complexa (LEFF, 2009).

Segundo Foladori (2001), a crise ambiental está associada às relações sociais do modo de produção capitalista e, para entendê-la, faz-se necessário compreender as contradições sociais que a provocam. No âmbito de um sistema fundamentado na competição e nas exigências de rentabilidade, na corrida pelo lucro rápido considerado o principal responsável pela destruição dos equilíbrios naturais, intensifica-se a degradação ambiental a partir de altos custos ecológicos.

Espaços litorâneos podem ser inseridos nesse contexto, assim como as comunidades que residem nestas áreas. Observa-se que estes espaços podem ser utilizadas como degraus na escalada para o crescimento econômico a qualquer custo, a despeito da qualidade de vida experimentada por seus ancestrais.

O local escolhido para a pesquisa foi o povoado de Carnaubeiras situado no município de Araioses no estado do Maranhão, que fica na mesorregião Leste Maranhense, na microrregião do Baixo Parnaíba. O local é considerado um dos grandes polos de extrativismo marinho do estado (ICMBIO, 2009). O povoado de Carnaubeiras está situado em uma extensa faixa de manguezal e de relevante produção extrativista. O local encontra-se na área de entorno da Reserva Extrativista (RESEX) Marinha do Delta do Parnaíba, que por sua vez está sobreposta na Área de Proteção Ambiental (APA) do Delta do Parnaíba. Ambas as Unidades de Conservação Federais estão sob responsabilidade do Instituto Chico Mendes de Conservação da Biodiversidade (ICMBIO). O povoado possui características únicas e relevantes para o município e para a região, dentre elas, destaca-se o fato de ser a mais antiga ocupação da região do Delta do Parnaíba (SEBRAE, 2003) e de possuir uma localização privilegiada, configurando-se como um dos principais pontos de saída para o Delta do Parnaíba, situado na divisa entre Maranhão e Piauí e nas proximidades do mercado consumidor do estado do Ceará.

Apesar do estado do Maranhão ser detentor da maior área do Delta do Parnaíba, é o estado do Piauí, estado vizinho, que possui maiores vantagens na exploração dos recursos pesqueiros encontrados no Delta do Parnaíba (MMA, 2002). Embora a extração e a comercialização de crustáceos abasteçam os estados do Ceará, Piauí e 
Alagoas, não é possível perceber o retorno socioeconômico desta atividade para o povoado de Carnaubeiras.

No extrativismo dos recursos marinhos podem ser destacados na produção do povoado o caranguejo-uçá, o pescado e a ostra. Estes produtos fazem parte do objeto de estudo deste artigo, sendo estas atividades extrativistas marinhas ainda praticadas tradicionalmente. Em Carnaubeiras, a maioria das famílias apresenta algum integrante envolvido com extrativismo marinho, contribuindo, assim, para a sobrevivência de suas famílias e a sustentabilidade da área.

A partir desses pressupostos, entende-se como é necessária uma análise dos processos produtivos e suas possíveis mudanças, resultantes da busca pelo desenvolvimento ocorrido nessa comunidade tradicional extrativista e verificando como o modelo econômico atual é vivenciado em suas múltiplas fases.

Dessa forma, a problemática aqui abordada consiste em tentar compreender como se dá a dinâmica das atividades produtivas extrativistas marinhas desenvolvidas no povoado de Carnaubeiras e os seus aspectos de sustentabilidade, analisando-os e relacionando-os aos princípios de sustentabilidade socioeconômica e ambiental desenvolvidos por Sachs (2004) em nível de uma comunidade tradicional extrativista, buscando compreender a complexidade de suas atividades produtivas e relações com o meio.

\section{Metodologia}

Em termos metodológicos, a pesquisa baseou seus resultados na análise qualitativa dos dados coletados por meio de questionários semiestruturados. Podendo, ainda, ser caracterizada como um estudo de caso, de natureza qualitativa, envolvendo análise de documentos, observação direta e entrevistas semiestruturadas com pescadores artesanais e catadores de caranguejo.

O método qualitativo adotado para a análise dos dados possibilitou o estudo de questões que não poderiam ser quantificadas, como os aspectos de subjetividade e atitudes individuais que são pertencentes ao contexto das relações sociais (BECKER, 1993).

Uma vez definidas quais seriam as atividades produtivas extrativistas marinhas de Carnaubeiras a serem estudadas, realizou-se a etapa da pesquisa de campo, para a coleta de dados referentes a essas atividades consideradas mais relevantes para o povoado. Foram realizadas 31 entrevistas e aplicados 31 questionários semiestruturados com os atores sociais para identificar quais são as principais atividades produtivas e a participação da comunidade. Também foram realizadas entrevistas semiestruturadas com o secretário de Turismo e Meio Ambiente do município, com o líder comunitário de Carnaubeiras e com o chefe dos agentes 
ambientais do ICMBIO - órgão responsável pela fiscalização da área da Reserva Extrativista Marinha.

Também foi realizado um levantamento documental sobre as medidas tomadas pelo Estado e pelo setor privado para a criação de infraestrutura básica, voltada para a prática de atividades produtivas sustentáveis.

A pesquisa de campo foi realizada nos períodos de defeso da cata do caranguejouçá na localidade, nos meses de novembro (sete dias) do ano de 2014 e nos meses de janeiro (sete dias) e março (sete dias) do ano 2015. Os dados coletados por meio dos questionários não tiveram a pretensão de realizar uma representação apenas quantitativa, mas, também, de tentar demonstrar a complexidade das relações entre os trabalhadores extrativistas e a sustentabilidade de suas atividades desenvolvidas na área da RESEX, o contexto destas relações e a profundidade das mesmas.

\section{A insustentabilidade do modelo de desenvolvimento atual}

Segundo Beck (1999), vive-se em um mundo fora de controle, onde não há nada seguro, apenas incertezas. Hardin (1968) já anunciava a "tragédia do uso de bens comuns", o qual a consolidação do mundo capitalista e globalizado, tendo o consumismo como uma de suas principais características, comprometeria a prosperidade da civilização. A mesma afirmação já havia sido apontada por Thomas Malthus (Século XVIII) cem anos antes em sua obra Ensaio sobre o princípio da população, em que mostrava a realidade dos recursos limitados e o perigo do crescimento desenfreado da população mundial.

De acordo com Sachs (2002), surgem questionamentos sobre o estilo de desenvolvimento sustentável adotado no sistema atual, principalmente quando se observa que este é predatório na utilização dos recursos naturais, socialmente perverso com geração de pobreza e de desigualdade social, politicamente injusto com concentração e abuso de poder, culturalmente alienador em relação aos seus próprios valores e eticamente censurável no tocante aos direitos humanos e das demais espécies.

O conceito de sustentabilidade comporta aspectos ou dimensões principais, chamados por esse autor de princípios de sustentabilidade, dos quais se pretendeu aqui selecionar três dos mesmos, a saber:

Sustentabilidade Social - melhoria da qualidade de vida da população, equidade na distribuição de renda e de diminuição das diferenças sociais, com participação e organização popular; 
Sustentabilidade Econômica - públicos e privados, regularização do fluxo desses investimentos, compatibilidade entre padrões de produção e consumo, equilíbrio de balanço de pagamento, acesso à ciência e tecnologia;

Sustentabilidade Ambiental - conservação geográfica, equilíbrio de ecossistemas, erradicação da pobreza e da exclusão, respeito aos direitos humanos e integração social. Abarca todas as dimensões anteriores por meio de processos complexos.

Hart e Milstein (2003) destacam o desenvolvimento sustentável como um processo para alcançar o desenvolvimento humano de uma maneira segura, igualitária, prudente e inclusiva. Para ser sustentável, por conseguinte, deve-se contribuir para o desenvolvimento sustentável ao gerar, simultaneamente, benefícios econômicos, sociais e ambientais, conhecidos como os três pilares sustentáveis.

Entende-se que as questões que envolvem a problemática ambiental e o Desenvolvimento Sustentável precisam ir além da fomentação de práticas ecologicamente "corretas" e ambientalmente sustentáveis, já que a gênese de tudo isso está vinculada à dinâmica do capitalismo econômico, que, para Mészáros (2002), é capaz de transformar potencialidades positivas em realidades destrutivas. Para Mészáros (2007), o termo "desenvolvimento" refere-se às condições de reprodução do sistema capitalista e a sua lógica de acumulação apenas fundamentada no produtivismo.

O modo de produção capitalista vem, então, alterando as relações entre a sociedade e a natureza. Inicialmente em relação à terra, que deixou de ser utilizada apenas para fins cultiváveis, e, depois, no que se refere à apropriação da mão de obra humana - a força do trabalhador.

Em seu livro A Grande Transformação, Polanyi (1944) fala da Revolução Industrial que aconteceu no Século XVIII, onde o progresso nos instrumentos de produção foi acompanhado de uma desarticulação nas vidas das pessoas, que "triturou como um moinho satanico os homens, transformando-os em massa". O antigo tecido social foi então destruído e, assim, foi tentada, sem sucesso, uma nova integração entre o homem e a natureza.

O homem e a terra foram transformados em mercadoria e a organização produtiva se viu ameaçada por conta da mudança no nível dos preços. E à medida que essa relação entre homem e natureza passou a ser medida pela produção de mercadorias, deu-se início à degradação ambiental, estabelecendo-se apenas o domínio humano sobre a natureza. 


\section{O povoado de Carnaubeiras e sua relação com a Resex Marinha do Delta do Parnaíba}

Segundo Costa (2002), uma Resex é uma área utilizada por populações extrativistas tradicionais cuja subsistência baseia-se no extrativismo, sendo permitida a prática de atividades complementares e de subsistência, como a agricultura e a criação de animais de pequeno porte. Além disso, tem como objetivo básico a proteção dos meios de vida e cultura dessas populações, assim como assegurar o uso sustentável dos recursos naturais na área da Resex.

Diante do cenário político e ideológico de criação das Unidades de Conservação, chama-se atenção para o termo "populações tradicionais" que ao longo dos debates sobre a criação dessas áreas protegidas tiveram no movimento socioambiental o apoio e incentivo à luta por seus direitos. Segundo Lima (1997), o surgimento de novas modalidades de Unidades de Conservação proporcionou a garantia de permanência dessas populações nessas áreas.

Esta situação torna-se ainda mais crítica, porque boa parte destas comunidades tradicionais estão situadas nas fronteiras da expansão das atividades capitalistas (ACSELRAD, 2010), sendo necessário, por esta razão, pensar na questão da governança ambiental, que levanta uma reflexão com propostas de ações em torno das formas de obtenção dos recursos naturais e o desenvolvimento sustentável das comunidades tradicionais presentes em Unidades de Conservação.

$\mathrm{Na}$ área do Delta do Parnaíba existem duas Unidades de Conservação Federais, a APA do Delta do Parnaíba e a Resex Marinha do Delta do Parnaíba, ambas sendo fiscalizadas e monitoradas pelo ICMBIO. A Resex Marinha do Delta do Parnaíba abrange um município do estado do Piauí, Ilha Grande de Santa Isabel, e dois maranhenses: Araioses e Água Doce. No interior da Resex estão cinco comunidades: Canárias, Passarinho, Caiçara, Morro do Meio e Torto (Figura 1). Porém, além dessas, outras comunidades são consideradas beneficiárias, ou seja, fazem uso dos recursos naturais extraídos na área da Resex de forma direta e tradicional. São elas: Ilha Grande, no Piauí; Carnaubeiras-Araioses, Barreiras, Bolacho, Barreirinha, Pedrinhas, Coqueiro e Água Doce pertencentes ao Estado do Maranhão (Figura 1). Das atividades produtivas desenvolvidas na Resex, destacam-se a cata de caranguejo, a pesca e o cultivo de arroz.

Todas as atividades produtivas extrativistas marinhas do povoado de Carnaubeiras são realizadas na área da RESEX do Delta do Parnaíba. Essa Unidade de Conservação foi criada pelo Decreto $S / N^{o}$ de $16 / 11 / 00$, sendo caracterizada como uma área protegida de Bioma Marinho Costeiro. 
Figura 1 - Localização geográfica da RESEX Marinha do Delta do Parnaíba (PI/ MA)

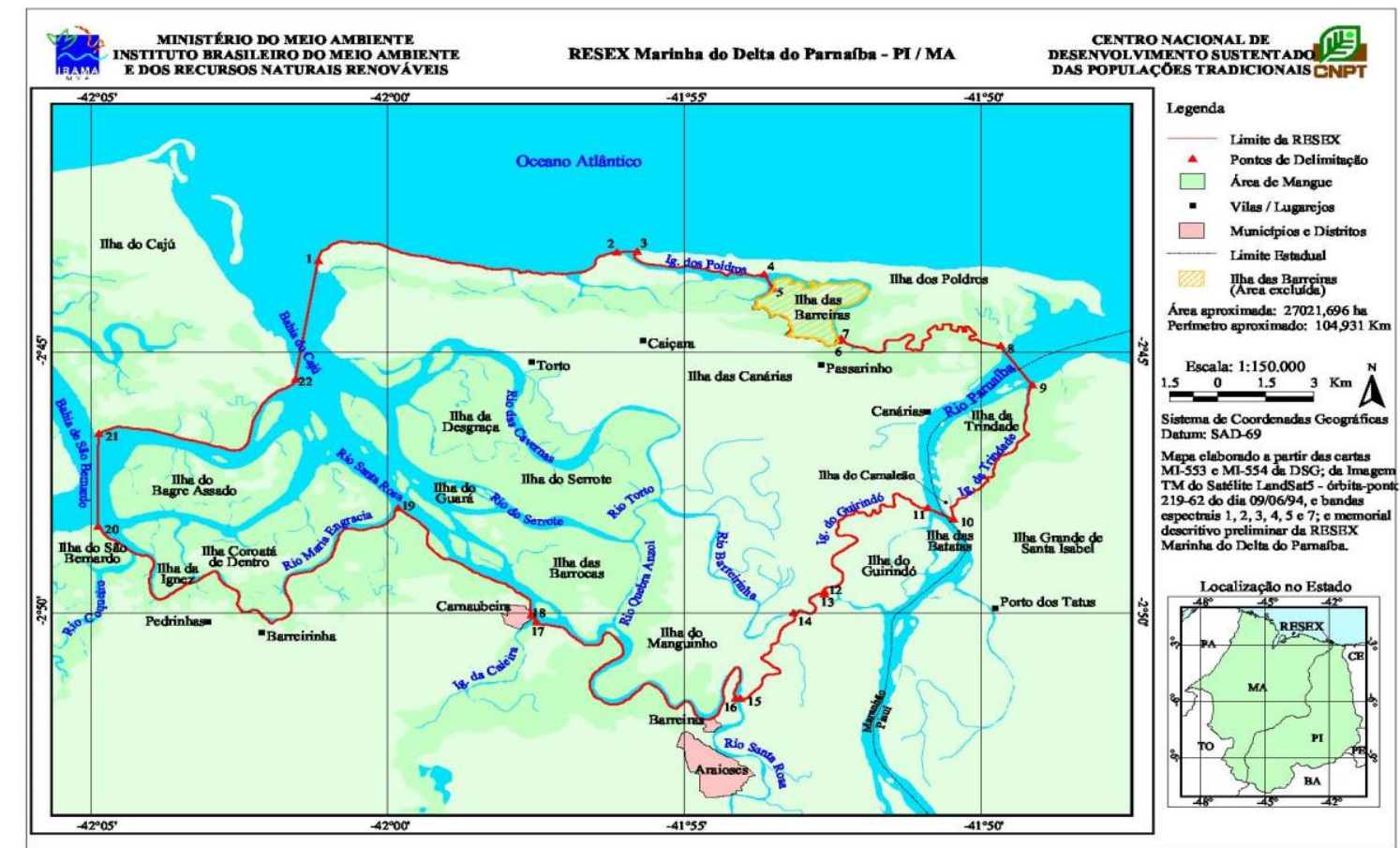

Fonte: ICMBIO (2009).

A pesca artesanal, a cata de caranguejo e da ostra, assim como qualquer outra atividade, quando realizadas no interior da Unidade de Conservação, devem ser fiscalizadas e monitoradas pelo órgão competente responsável pela área de 2.700 $\mathrm{km}^{2}$. É nesse momento que surgem os conflitos ambientais em relação à criação da própria Resex, de suas formas de fiscalização e das medidas punitivas para as ações consideradas como proibidas ou crimes ambientais na área protegida por lei.

\section{Coleta de dados e avaliação da sustentabilidade das atividades produtivas extrativistas}

Para a formulação deste trabalho, como antes supracitado, foram coletados dados qualitativos e quantitativos no povoado de Carnaubeiras por meio de questionários, entrevistas e observações realizadas no local. A partir destes dados, foi feita a análise da dinâmica das atividades produtivas extrativistas marinhas desenvolvidas pelos trabalhadores na área da Resex do Delta do Parnaíba, assim como seus aspectos de sustentabilidade social, ambiental e econômica em relação aos princípios propostos por Sachs (2002). Nesse contexto, tendo em vista as atividades produtivas e relevantes na comunidade de Carnuabeiras para sua 
reprodução social, enquanto comunidade tradicional, são essas atividades extrativistas marinhas as que melhor representam a forma como os sujeitos sociais presentes nessa área relacionam-se com o meio ambiente.

Conforme os dados do Quadro 1, foram entrevistados mais indivíduos do sexo masculino do que feminino, isto porque as atividades extrativistas marinhas ainda são mais praticadas por homens. Eles apresentam uma faixa etária entre 13 e 61 anos, com destaque para os ofícios de pescador e catador. Enquanto os homens estão nas áreas de extração, é comum encontrar mulheres cuidando da casa e dos filhos. Quando estes trabalhadores foram perguntados sobre a escolaridade, 48\% dos entrevistados declararam ser analfabetos. Quando questionados sobre a renda familiar, afirmaram obter uma renda inferior a um dólar por dia (equivalente a $R \$$ 3,16) - segundo dados do Banco Central do Brasil de 2016. Diante disso, é possível afirmar que a condição atual da renda desses trabalhadores pode ser considerada como próxima da extrema pobreza. 
Quadro 1: Sistematização do grupo de extrativistas marinhos entrevistados

\begin{tabular}{|c|c|c|c|}
\hline Extrativista & Gênero & Profissão & $\begin{array}{l}\text { Tempo de } \\
\text { Trabalho }\end{array}$ \\
\hline Extrativista 1 & Masculino & Catador de caranguejo & 15 anos \\
\hline Extrativista 2 & Masculino & Pescador artesanal & 34 anos \\
\hline Extrativista 3 & Masculino & Pescador artesanal & 41 anos \\
\hline Extrativista 4 & Masculino & Pescador artesanal & 33 anos \\
\hline Extrativista 5 & Masculino & $\begin{array}{l}\text { Catador de caranguejo e pescador } \\
\text { artesanal }\end{array}$ & 11 anos \\
\hline Extrativista 6 & Masculino & $\begin{array}{l}\text { Catador de caranguejo e pescador } \\
\text { artesanal }\end{array}$ & 21 anos \\
\hline Extrativista 7 & Masculino & Pescador artesanal & 21 anos \\
\hline Extrativista 8 & Feminino & Catadora de ostra e pescadora artesanal & 32 anos \\
\hline Extrativista 9 & Feminino & Pescadora artesanal & 46 anos \\
\hline Extrativista 10 & Masculino & Catador de caranguejo & 20 anos \\
\hline Extrativista 11 & Masculino & Pescador artesanal & 24 anos \\
\hline Extrativista 12 & Masculino & Pescador artesanal & 22 anos \\
\hline Extrativista 13 & Masculino & Pescador artesanal & 24 anos \\
\hline Extrativista 14 & Feminino & Pescadora artesanal & 17 anos \\
\hline Extrativista 15 & Masculino & $\begin{array}{l}\text { Catador de caranguejo e pescador } \\
\text { artesanal }\end{array}$ & 61 anos \\
\hline Extrativista 16 & Masculino & $\begin{array}{l}\text { Catador de caranguejo e pescador } \\
\text { artesanal }\end{array}$ & 36 anos \\
\hline Extrativista 17 & Masculino & Pescador artesanal & 23 anos \\
\hline Extrativista 18 & Masculino & Pescador artesanal & 21 anos \\
\hline Extrativista 19 & Masculino & $\begin{array}{l}\text { Catador de caranguejo e pescador } \\
\text { artesanal }\end{array}$ & 41 anos \\
\hline Extrativista 20 & Masculino & $\begin{array}{l}\text { Catador de caranguejo e pescador } \\
\text { artesanal }\end{array}$ & 37 anos \\
\hline Extrativista 21 & Masculino & $\begin{array}{l}\text { Catador de caranguejo e pescador } \\
\text { artesanal }\end{array}$ & 34 anos \\
\hline Extrativista 22 & Masculino & $\begin{array}{l}\text { Catador de caranguejo e pescador } \\
\text { artesanal }\end{array}$ & 23 anos \\
\hline Extrativista 23 & Masculino & Pescador artesanal & 30 anos \\
\hline Extrativista 24 & Feminino & Catadora de ostra e pescadora artesanal & 35 anos \\
\hline Extrativista 25 & Feminino & Pescadora artesanal & 24 anos \\
\hline Extrativista 26 & Feminino & Catadora de ostra & 5 anos \\
\hline Extrativista 27 & Masculino & Catador de ostra e pescador artesanal & 16 anos \\
\hline Extrativista 28 & Masculino & Pescador artesanal & 47 anos \\
\hline Extrativista 29 & Masculino & Pescador artesanal & 32 anos \\
\hline Extrativista 30 & Masculino & $\begin{array}{l}\text { Pescador artesanal e catador de } \\
\text { caranguejo }\end{array}$ & 36 anos \\
\hline Extrativista 31 & Masculino & Pescador artesanal & 38 anos \\
\hline
\end{tabular}

Fonte: Elaboração própria.

Foram selecionadas três atividades produtivas extrativistas marinhas consideradas de maior relevância para o povoado de Carnaubeiras, sendo estas de maior 
ocorrência, segundo os extrativistas (Quadro 1): a pesca do peixe, a cata do caranguejo e da ostra, todas praticadas de forma artesanal.

As atividades aqui expostas são realizadas por pequenos grupos, sejam eles compostos por integrantes da família ou por companheiros de trabalho, com algumas exceções para a cata da ostra, que também é praticada de forma individual. Os materiais utilizados para a realização dessas atividades, quando feitas em grupo, como barco, botes, redes e etc. são compartilhados, assim como as despesas com gelo e combustível quando necessário. A maior parte das embarcações na localidade ainda são a remo.

\section{A captura do caranguejo-uçá (ucides cordatus) e o Catador de Caranguejo}

"Se o caranguejo acabar eu não sei não..., por isso não quero que acabe. Vivo disso". João Batista - Catador de caranguejo

$\mathrm{Na}$ região do Delta do Parnaíba, o caranguejo-uçá é considerado o principal recurso pesqueiro encontrado na localidade. A captura dessa espécie de caranguejo é tida como uma atividade extrativista tradicional nos povoados da região do Delta do Parnaíba e na comunidade de Carnaubeiras. A cata do caranguejo-uçá é a principal atividade extrativista marinha geradora de renda, pois trata-se do produto de maior exportação do povoado para os estados do Piauí e Ceará, sendo também uma das principais fontes de alimento para a população local.

O caranguejo-uçá desempenha uma importante função no processo de manutenção do ecossistema manguezal, tendo papel ecológico relevante na cadeia alimentar dos diferentes ciclos biológicos de elementos que compõe a biodiversidade na área, atuando também na oxigenação e drenagem dos sedimentos através da escavação das tocas, promovendo a aceleração do ciclo dos nutrientes (JONES, 1984).

Quando existe a proposta de compra apenas da carne do caranguejo, estes são levados para as residências dos catadores e dá-se início ao processo de beneficiamento da produção, que consiste em limpar o caranguejo, cozinhar e retirar a carne para a comercialização. Neste processo conta-se com a participação não apenas das mulheres, mas também de crianças. Parte desse caranguejo é comercializado no mercado interno do próprio povoado e uma quantidade bem inferior da produção é destinada ao mercado externo, que é transportada para cidades como Teresina (PI) e Fortaleza (CE) por se tratarem de importantes mercados consumidores a distâncias pequenas do município de Araioses (MA) cerca de 350 e 500 quilômetros, respectivamente. 
A rotina de trabalho é árdua e começa nas primeiras horas do dia, quando os catadores de caranguejo saem em grupos compostos por parceiros de trabalho ou membros da família. A diversidade na faixa etária desses trabalhadores é variável, podendo encontrar inclusive crianças durante o desenvolvimento da atividade. Quando saem para a cata do caranguejo, chegam a ficar em média de quatro a seis horas imersos no mangue, esforçando-se para tentar retirar o máximo. O esforço realizado para obtenção de uma quantidade maior de caranguejos na atividade extrativista faz-se necessário tanto para atender a demanda do mercado consumidor quanto para obter maior lucratividade para esses trabalhadores, já que os valores recebidos são baixíssimos. Para alcançar uma produção maior, alguns catadores fazem uso de drogas lícitas (álcool e cigarro) e também ilícitas (maconha e crack) para suportar a dura rotina de extração do caranguejo-uçá. Quanto mais tempo no mangue, maior a produção, o que remete a uma reflexão sobre a natureza desta atividade e sua sustentabilidade social e ambiental.

Mesmo com a dura rotina e das insalubres condições de trabalho, a renda por mês obtida nesta atividade é inferior a um salário mínimo, variando entre $\mathrm{R} \$ 100$ e $\mathrm{R} \$$ 300. Diante deste cenário, o trabalhador é obrigado a acumular a atividade de extração de caranguejo com a pesca (peixe e camarão), a cata da ostra e a agricultura familiar, cultivando principalmente a mandioca para fabricação de farinha.

Para Nordi (1992), os catadores de caranguejo fazem parte do grupo de pescadores artesanais com menor poder aquisitivo. São extremamente pobres, pouco reconhecidos, atuando à margem da organização da produção, não sendo identificados no cadastro como pescadores, mas como trabalhadores informais (IBAMA, 1994), não tendo acesso a direitos trabalhistas.

Uma pesquisa desenvolvida pela Codevasf (2012), aponta que os dias trabalhados pelos catadores variam de acordo com o nível de captura durante o ano. De dezembro a março, trabalham aproximadamente cinco dias extraindo de 60 a 80 unidades de caranguejo-uçá por catador durante o dia, e no resto do ano, trabalham em média três dias durante a semana, capturando de 30 a 40 unidades por dia. Estes dados apontam para uma demanda maior nos meses de dezembro a março, período de defeso da espécie, em que a cata do caranguejo-uçá é proibida. O que se comprovou na pesquisa de campo é que esta interrupção da cata do crustáceo é pouco respeitada, por motivos de inconsciência ambiental e da pressão exercida pelo mercado. Segundo Lustosa (2005), a atividade extrativista do caranguejo-uçá corresponde ao maior volume de produção pesqueira do Delta do Parnaíba.

A técnica mais utilizada para a cata é chamada de braceamento, que consiste em o catador de caranguejo estender-se sobre a lama úmida e fria, sem nenhuma proteção adequada, inserindo o braço até alcançar o caranguejo na toca. Algumas das consequências negativas desse método são as várias lesões que podem ocorrer 
no corpo do extrativista, como arranhões nas mãos e nos braços, problemas de pele pelo constante contato com a lama e até inflamações nos olhos e ouvidos. Outra técnica também utilizada é o tapamento, em que o catador cobre a toca do caranguejo com sedimentos do mangue - estes são empurrados com os pés - após tapar certo número de tocas, o catador aguarda o caranguejo subir até a superfície em busca de oxigênio, capturando assim o animal.

\section{Transporte e comercialização do caranguejo}

A comercialização de cada caranguejo apresenta valores variáveis, dependendo do tamanho dos animais: o maior custando $\mathrm{R} \$ 1,25$, o médio $\mathrm{R} \$ 0,80$ e o pequeno $\mathrm{R} \$$ 0,30. Esses valores nem sempre são pagos de forma devida no ato da entrega do produto para o atravessador (Figura 3). Eventualmente esses trabalhadores recebem o pagamento em um momento posterior. Em alguns casos, a produção serve para pagar dívidas já existentes de remédios, comida ou bebidas alcoólicas.

Depois de amarrados um a um, os caranguejos são transportados até o porto, onde os atravessadores aguardam para novamente serem contados e preparados para viajarem até o Porto dos Tatus, no município de Ilha Grande (PI), onde serão comercializados. Do Porto dos Tatus, são levados até Teresina, Fortaleza e outros municípios em caminhões sem nenhuma infraestrutura adequada para a manutenção da vida desses animais, pois são amontoados em pilhas e cobertos com lona. A exposição ao sol e às altas temperaturas acabam causando desidratação e levando muitos caranguejos à morte, antes mesmo da chegada ao ponto de destino. 
Figura 3 - Armazenamento para o transporte do caranguejo-uçá.

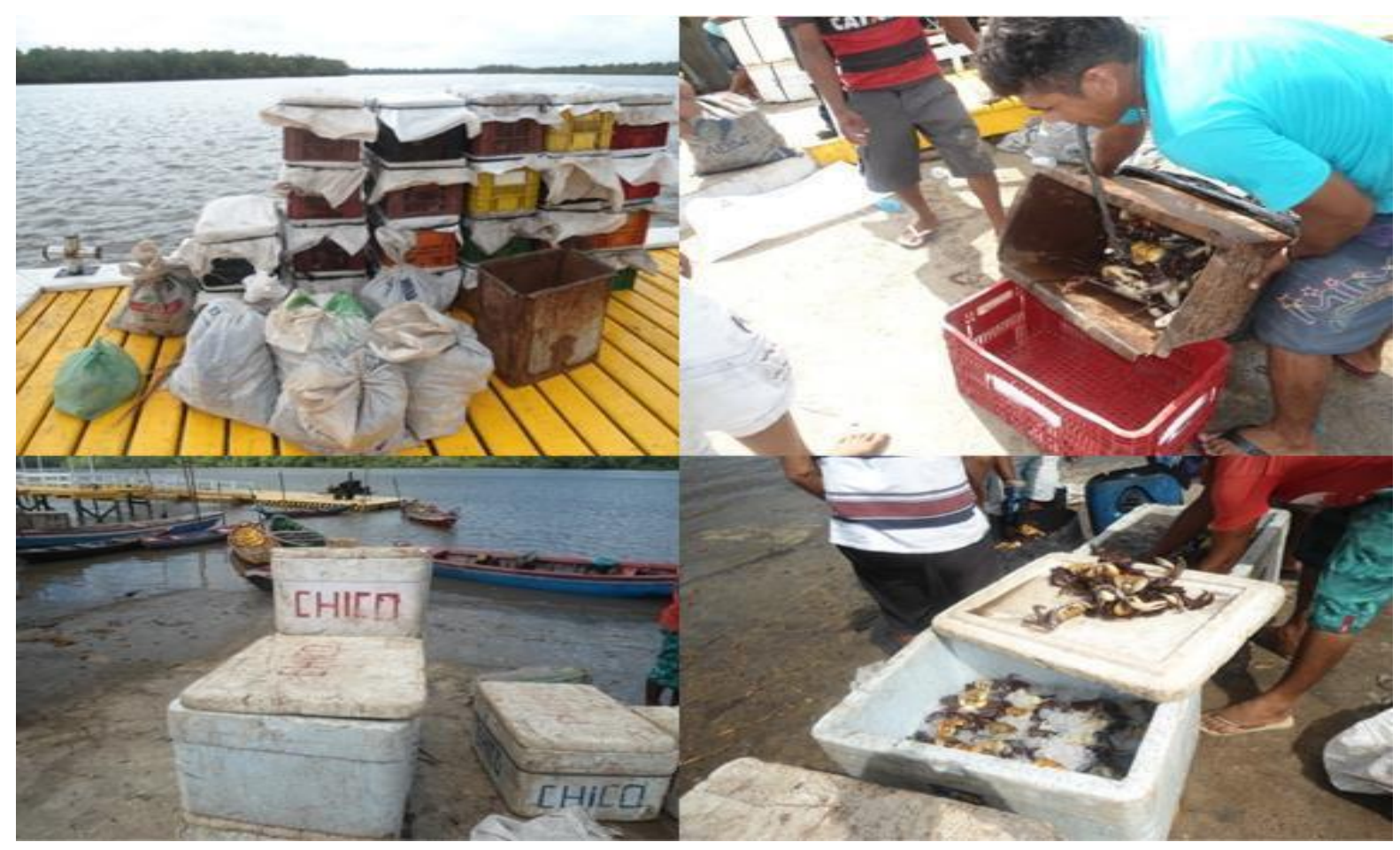

Fonte: Acervo dos autores.

Segundo a Embrapa (2007) e Mota (2007), a maneira utilizada para o transporte dos caranguejos vivos, entre os locais de captura, até os locais onde serão consumidos, provoca perdas consideradas entre $40 \%$ e $60 \%$. O dado é preocupante, já que esses aspectos podem comprometer a saúde da espécie e sua exploração de forma sustentável, pois com números altos na perda da produção serão necessárias novas extrações para substituir o que foi perdido, podendo provocar a exaustão do ecossistema. Segundo dados da Embrapa (2007), estima-se que em média sejam capturados cerca de 20 milhões de caranguejos por ano na Resex do Delta do Parnaíba. A grande quantidade de canais encontrados nos manguezais da área, aliados a fatores como o número reduzido de fiscais ambientais, prejudica sensivelmente o acompanhamento estatístico de toda produção extrativista marinha no povoado de Carnaubeiras. 


\section{A retirada da ostra}

"Ah, o que a gente ganha é muito pouquinho. Só dá pra ir sobrevivendo, nós e os filhos... vamos vivendo, né?" Maria da Conceição - Catadora de ostra

A atividade extrativista marinha de cata da ostra também pode ser considerada uma prática relevante no povoado de Carnaubeiras, porém, é realizada em menor escala do que o caranguejo-uçá e o pescado. Dependendo do período de maior facilidade para a obtenção do produto, quando ele começa a dar sinais de escassez, os catadores de ostra associam esta atividade com a pesca artesanal ou com a cata do caranguejo.

A presença de mulheres é comum nesta atividade, sendo observada em maior número do que na cata do caranguejo e na pesca artesanal, estejam elas trabalhando sozinhas ou em companhia de seus maridos. Diferente das demais atividades, foi verificado que é comum a cata de ostra ser praticada de forma individual.

Apesar de ser um produto bastante procurado e valorizado nas barracas de comercialização em praias do litoral nordestino, a ostra vendida no povoado de Carnaubeiras pode ser encontrada por um preço muito abaixo do valor de mercado. Assim como os catadores de caranguejo, os catadores de ostra vendem a sua produção no porto de embarque e desembarque de barcos na entrada do povoado. A comercialização ocorre para compradores locais ou para os atravessadores que repassam o produto para outros estados, como Piauí e Ceará.

O tipo de ostra encontrada na área é a "ostra do manguezal" que também pode ser encontrada entre o sul do Caribe e o Uruguai (RIOS, 1994). Este é um nome popular dado a duas espécies nativas de ostras do gênero Crassostrea, que ocorrem em áreas estuarinas de baixa salinidade. A fixação desta espécie pode ser observada nas raízes das árvores dos manguezais, no mangue vermelho (Rhizophora mangle) ou em materiais de dura consistência encontrados nas águas que banham os manguezais. A ostra de pedra (C. brasiliana) é a espécie de maior tamanho e enquanto a ostra de mangue (C. mangle), é a menor.

Este tipo de extrativismo também pode ser caracterizado como rudimentar pela forma como ainda é praticado. $\mathrm{Na}$ atividade extrativista de retirada de ostras são usadas ferramentas simples como ganchos e cestos, quando podem ser encontradas em áreas mais rasas. Quando se encontram em canais de fundo rochoso, faz-se necessária habilidade para mergulhar em águas profundas para conseguir realizar a coleta da ostra, como mostra a Figura 4. 
Figura 4 - Catador de ostra em Carnaubeiras - Araioses

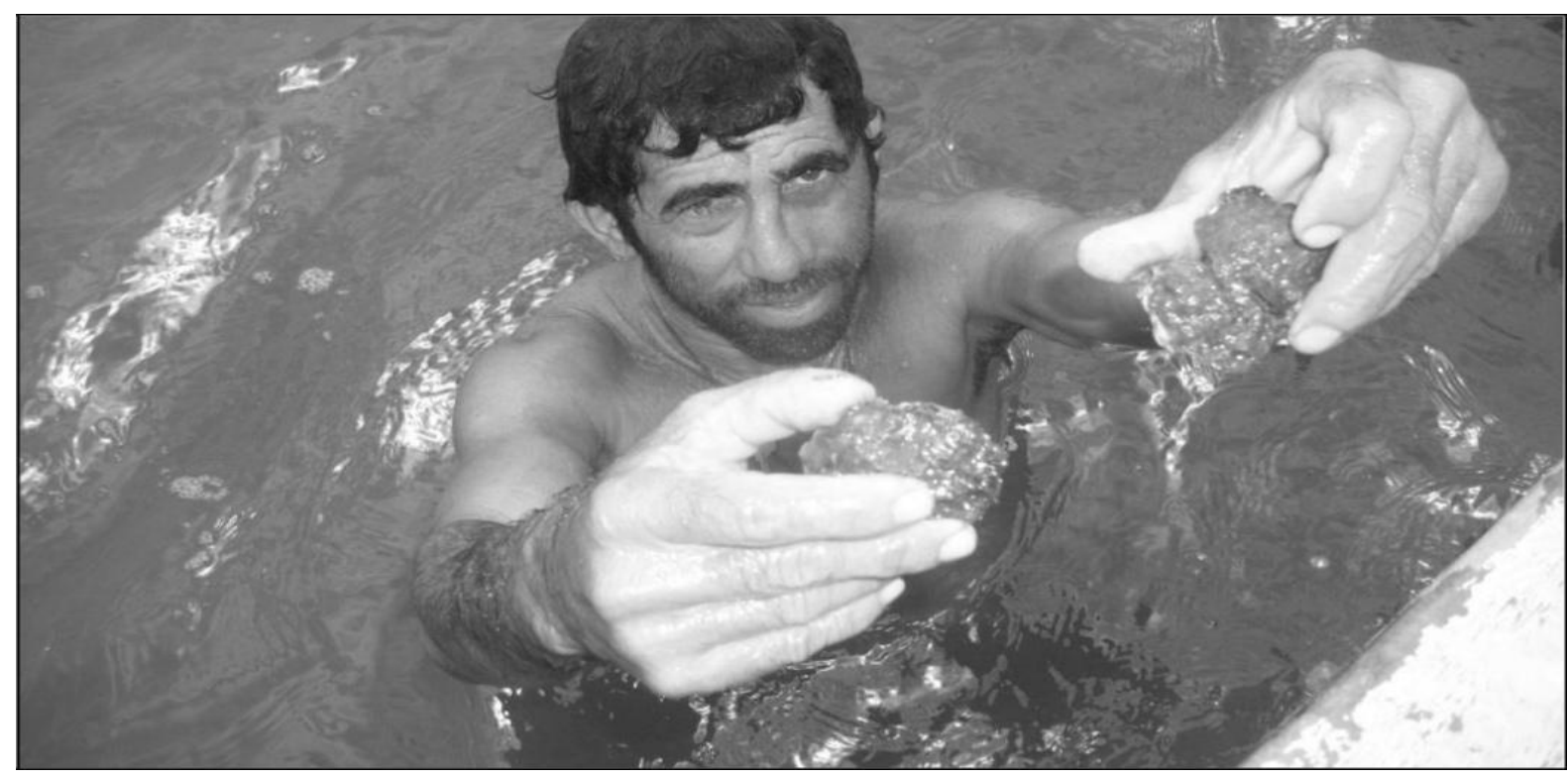

Fonte: Acervo dos autores.

Sobre a comercialização da produção de ostras em Carnaubeiras, não foi identificado uma produção em grande escala e nenhum tipo de infraestrutura adequada para o armazenamento e conservação, ou mesmo para o beneficiamento do produto, que também é comercializado para o estado de Fortaleza. Outro fator negativo está ligado à logística precária para a comercialização da produção, o que pode gerar perdas por mortalidade no transporte. Segundo Portella (2005), uma opção para a venda in natura da ostra seria o congelamento do produto, mas essa técnica ainda não é praticada pelos extrativistas no povoado.

O armazenamento é realizado em sacos de náilon e comercializado no porto do próprio povoado por meio dos atravessadores ${ }^{1}$. Pode-se constatar que a participação do atravessador na comercialização é total no extrativismo marinho do caranguejo e da ostra, o que já é menos expressivo na extração do peixe e do camarão. Foi identificado que os atravessadores são residentes no próprio povoado e exercem essa função em representação de compradores externos. Para os extrativistas marinhos da ostra, o atravessador é o principal financiador da atividade, pois será ele quem comprará toda produção, principalmente nos finais de semana, em que são tidos como a "salvação" para a venda do produto.

O exercício da atividade pode ser descontinuado por conta do mau tempo, pelo regime das marés e pela oportunidade de vendas. A captura da produção é feita de forma indiscriminada, o que inclui a falta de informação sobre a distribuição espacial e temporal dos locais de extração desse tipo de produção. O trabalho

\footnotetext{
${ }^{1}$ Os atravessadores são entendidos como agentes comerciais informais. Geralmente, residem no próprio povoado.
} 
diário dura em média de quatro a cinco horas, trabalhando entre cinco a seis dias na semana. Em média conseguem uma produção de cinco a 10 sacos de $50 \mathrm{~kg}$ por semana, que são vendidas para um único comprador, sendo este o empregador dos atravessadores residentes no povoado, caracterizando então uma espécie de monopólio comercial na área. Este comprador então adquire por R $\$ 70$ cada saco de ostra.

Segundo Sales e Moreira (1996), os atravessadores podem ser entendidos como agentes comuns à atividade pesqueira de pequena escala. Tal fato pode ser explicado pelo poder limitado dos pescadores sobre o mercado, fazendo com que estes atravessadores sejam considerados, portanto, agentes clandestinos. Sobre eles, também não foi identificado nenhum tipo de fiscalização efetiva durante a venda da produção comercializada no porto do povoado de Carnaubeiras.

\section{A pesca artesanal}

"Os peixes estão acabando, tem menos peixe que no passado... e não sabemos o que fazer." Antonio das Graças - Pescador

No que diz respeito à atividade extrativista marinha da pesca (Figura 5), observa-se que é comum entre os pescadores encontrar nas famílias do povoado pessoas que ainda trabalham utilizando objetos artesanais tradicionais como: tainheira, anzol, caçoeira, landuá, tarrafa, espinhel ou puçá.

Do total obtido em cada pescaria, parte é destinada para o consumo familiar e a outra é comercializada no porto principal do povoado. O transporte é feito em bianas à vela e canoas a remo ou ainda, em alguns casos, embarcações motorizadas (Figura 5). 
Figura 5. Pescadores artesanais utilizando a técnica do anzol

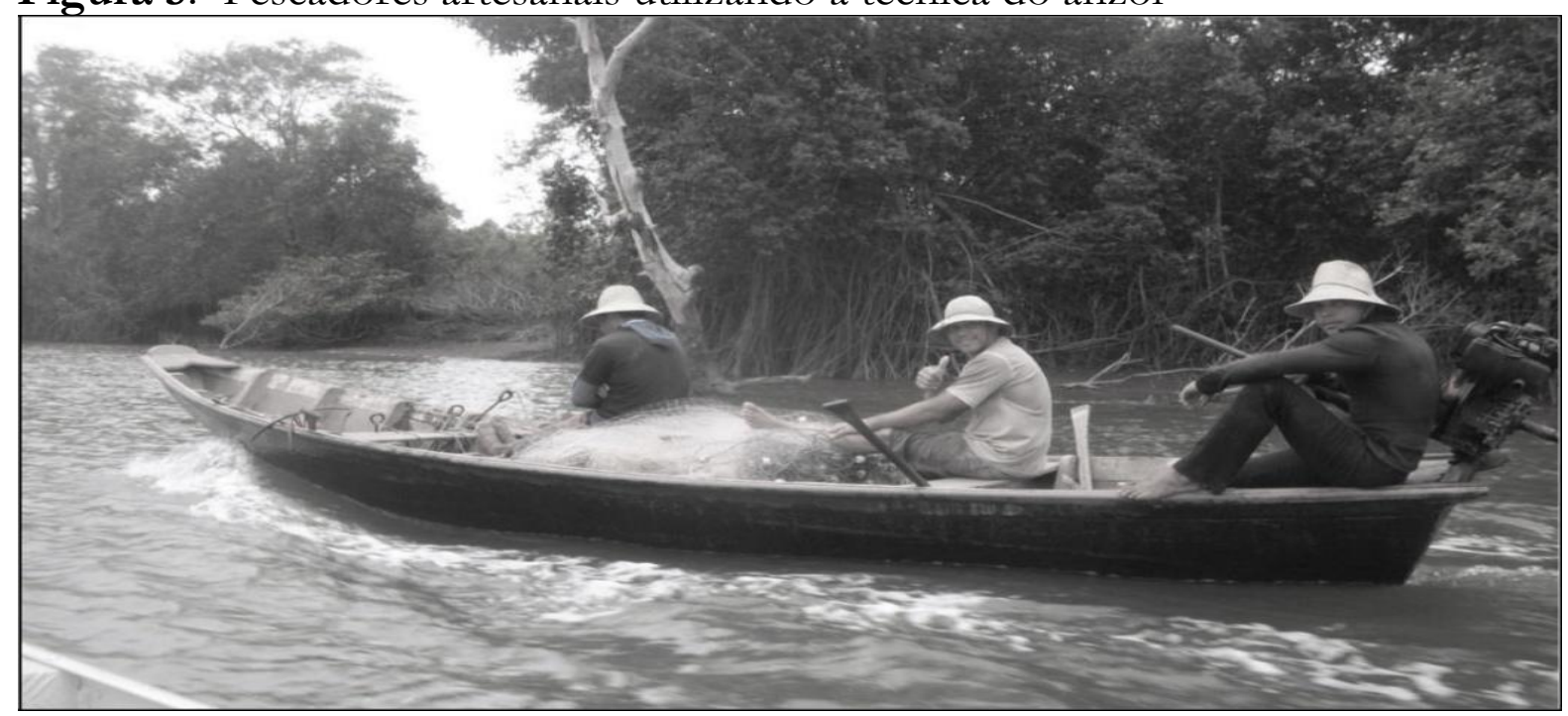

Fonte: Acervo dos autores.

A pesca em toda porção do litoral maranhense ainda é considerada artesanal, com destaque para a produção oriunda das embarcações movidas a remo e a vela (com comprimento de quatro a sete metros), o que representa $45,8 \%$ do total de embarcações do lado maranhense (IBAMA, 2005).

$\mathrm{O}$ tipo de pesca artesanal presente nessa área apresenta uma estrutura complexa e descentralizada. No que se refere às formas de organização dos próprios pescadores artesanais, não há uma articulação política e econômica sobre os modos de produção e comercialização do pescado. Os pescadores artesanais encontram-se desamparados neste sentido pelo poder público, o que resulta em uma série de problemas relacionados à insustentabilidade econômica desta atividade, pois o baixo retorno econômico que conseguem com o trabalhado exercido não tem sido suficiente para atender as necessidades básicas dos mesmos e de suas famílias.

Outros fatores que podem ser destacados como contribuintes para a insustentabilidade desta atividade são o baixo nível educacional e a ausência de conhecimento sobre as formas de organização e articulação. Esta condição dificulta a possibilidade de estruturação da prática da pesca no povoado de Carnaubeiras.

Meirelles (2012), ao realizar uma pesquisa na área do delta do Parnaíba, obteve a classificação de espécies capturadas nessa área. Por sua pesquisa ocorrer numa área próxima ao povoado, destacam-se aqui as principais espécies apontadas no estudo: camurupim (Megalops atlanticus), surubim (Pseudoplatystoma corruscans), mandubé (Ageneiosus brevifilis) e bagre uritinga (Arius proops).

Como citado anteriormente, estes trabalhadores saem em grupos, sendo sujeitos da mesma família ou conhecidos do povoado, para a prática da atividade 
pesqueira. Nas entrevistas realizadas com os pescadores, observou-se que 64\% afirmaram sair para a pesca no período propício da maré, demonstrando obter profundo conhecimento em relação aos tempos adequados para a pesca e aos melhores lugares para encontrar o pescado. O conhecimento adquirido ao longo da vida e através dos seus progenitores ainda tem vasta aplicação em todas as áreas da prática da pesca artesanal atual, apesar de que as mudanças em seu modo de vida já são perceptíveis.

As novas configurações socioespaciais oriundas do modo exploratório de produção econômica vêm tomando espaço e dando origem a um processo de mudanças no modo de vida destes pescadores artesanais, modificando as formas de convívio social e as relações de trabalho. Acredita-se que tais configurações podem ter originado espaços de exclusão e marginalização observados dentro da comunidade, descaracterizando-a como uma comunidade tradicional.

Toda a pesca é praticada de forma ainda rudimentar. Os pescadores saem para pescar quando ocorre a vazante da maré e, quando ela começa a encher, retornam, levando em consideração essa rotina, que é organizada de acordo com os aspectos naturais da área.

A falta de infraestrutura para a captura, o armazenamento e a comercialização do pescado neste tipo de atividade também é um problema a ser apontado. Segundo o ICMBIO (2009), recomenda-se que para qualquer ação planejada para essa área não se deve haver o viés desenvolvimentista ou tecnicista, levando, portanto, em consideração as questões dos estoques, da ecologia pesqueira e também dos aspectos socioculturais e históricos dos pescadores.

Entende-se que o problema torna-se ainda mais complexo diante do fato de que a pesca artesanal, a cata do caranguejo e da ostra são atividades extrativistas marinhas que não seriam tão impactantes ao meio ambiente se na reprodução social dessa comunidade tradicional extrativista não houvesse a constante pressão do mercado capitalista, que tem exigido uma produção cada vez maior, porém mantendo preços baixos.

O saber local pode ser considerado uma expressão única de um grupo social. Sua visão de mundo, seu jeito de ser e viver, a relação com o contexto em que está inserido e com os outros sujeitos que possam, de alguma forma, relacionar-se com esse grupo, revela particularidades sociais. Para o pescador artesanal, o trabalho é resultante de sua liberdade, caracterizando-se como um ser não subordinado a um "patrão". O trabalho e resistência diante das adversidades demonstram um modo de vida desprendido de maiores ambições, embora sejam assediados pelo fetiche do capital. Os pescadores ainda preservam a simplicidade e a liberdade em seus modos de vida e trabalho.

O aspecto de "liberdade" constatado no modo de vida desses pescadores encontra sua justificativa na arte da pesca como meio de produção, expressando um modo de resistência ao sistema vigente (DIEGUES, 1983). 
Para Diegues (1983), o pescador artesanal difere-se dos demais trabalhadores artesanais, pois estes adaptam seus instrumentos a uma matéria-prima homogênea. Já o pescador artesanal, ao contrário, é obrigado a dominar o manejo de diferentes instrumentos para distintas espécies num meio de constantes mudanças. Todos esses trabalhadores carregam consigo um diversificado acervo de informações e conhecimentos, tornando-os também parte da riqueza desse lugar. Os extrativistas marinhos detêm conhecimentos específicos fundamentais para a prática do trabalho que exercem.

\title{
Os princípios de sustentabilidade propostos por Sachs em comparação aos princípios de sustentabilidade vivenciados no povoado de Carnaubeiras
}

\author{
"A única coisa que pretendo deixar pros meus filhos é a profissão e a honestidade." \\ Carlos dos Santos - Pescador
}

Os princípios de sustentabilidade abordados por Ignacy Sachs (2008) e destacados nessa pesquisa conduzem para uma reflexão sobre a aplicabilidade da proposta de Desenvolvimento Sustentável comparando-a com a realidade vivenciada pelos extrativistas marinhos e por toda comunidade do povoado de Carnaubeiras, ambos detentores do importante papel na conservação e preservação dos recursos naturais nessa área do Delta do Parnaíba. O referencial de desenvolvimento amparado pelo Estado brasileiro, mesmo que destacado em projetos direcionados para a área, vem subordinando o bem-estar social e ambiental aos interesses de expansão do capital por meio da exploração dos recursos naturais e da força de trabalho dos extrativistas marinhos presentes na área.

A partir dos dados obtidos na pesquisa qualitativa e quantitativa, foi possível verificar que em relação às atividades produtivas marinhas desenvolvidas no povoado de Carnaubeiras na área da RESEX existem problemas relacionados aos princípios de sustentabilidade que foram destacados segundo Sachs (1986; 1993, 2002, 2004, 2008) em capítulos anteriores. Estes problemas estão listados abaixo:

- Ausência de organizações sociais eficientes livres de paternalismo e de forças do poder local;

- Ausência de infraestrutura adequada para a prática e comercialização da produção extrativista marinha do povoado;

- Baixos salários e condições subumanas de trabalho, sendo que a necessidade de produção cada vez maior exige dos trabalhadores extrativistas, principalmente dos catadores de caranguejo, maior tempo de permanência na área do mangue;

- Ausência de capacitação dos extrativistas marinhos (Em relação às UC's e demais atividades na área); 
- Ausência de maior efetividade na fiscalização exercida pelos órgãos gestores da Unidade de Conservação sobre os atacadistas que atuam na área;

- Pesca predatória;

- Sobre-exploração de recursos naturais;

- Ausência de maior diversidade de atividades desenvolvidas na área do povoado para a obtenção de renda;

- Ausência de sistema de tratamento de água, esgoto e lixo na área do povoado, o que pode trazer sérios danos ao bioma local.

A relação entre a pobreza e a degradação ambiental no povoado de Carnaubeiras parece estar inserida no que se pode definir como um "ciclo vicioso". $\mathrm{Na}$ contextualização local do povoado, dentro de uma escala temporal em que as relações entre o homem e a natureza são vistas como essenciais para a sobrevivência, são eslas também responsáveis pela degradação dos recursos naturais marinhos encontrados na área. Esse modelo de exploração dos recursos naturais no Delta do Parnaíba vem se efetivando de forma insustentável ao considerar-se os princípios propostos por Ignacy Sachs. A falta de ação do Estado reflete na ausência de infraestrutura para a prática destas atividades extrativistas marinhas de forma sustentável, o que coloca o interesse de expansão do capital em detrimento do bem-estar social dessa comunidade tradicional.

Quando Sachs (2008) aponta critérios básicos para a garantia de sustentabilidade no caráter social, a proposta destaca para que haja um patamar razoável de homogeneidade, distribuição de renda justa, autonomia com qualidade de vida decente e igualdade no acesso aos serviços sociais.

Sobre a realidade atual do povoado de Carnaubeiras, existem contradições gritantes em relação às condições de sustentabilidade propostas. Os dados apresentados nesta pesquisa apontam que a maioria dos trabalhadores extrativistas marinhos entrevistados (70\%) ganha entre $\mathrm{R} \$ 100$ e $\mathrm{R} \$ 300$ por mês, valor abaixo do salário mínimo de $\mathrm{R} \$ 788,00$ em 2015. Pode-se, assim, também afirmar que o valor é insuficiente para a satisfação das condições básicas de sobrevivência. Apontando para este dado específico da distribuição de renda, entende-se que esse valor obtido é irrisório diante da lucratividade obtida por aqueles que comercializam essa produção - atravessadores que compram dos pequenos produtores e repassam ao mercado consumidor.

Em relação ao critério de sustentabilidade ambiental, Sachs (2008) enfatiza a necessidade de respeitar a capacidade de autodepuração dos ecossistemas, ou seja, seria preciso dar um período de descanso suficiente para a autopurificação do ecossistema de manguezal em Carnaubeiras. Isso é considerado inviável para os extrativistas que retiram uma produção cada vez maior para atender a demanda do mercado, embora estejam sujeitos a comercializar essa produção por um preço 
irrisório, dando continuidade ao processo de reprodução da desigualdade social por meio da alta exploração.

O uso racional dos recursos naturais nesse ponto pode ser considerado primordial para esse princípio de sustentabilidade, e para isso, seria necessário adotar padrões para a gestão dos recursos encontrados na área. Pelos relatos obtidos durante a pesquisa, alguns extrativistas marinhos demonstraram ter a percepção ambiental favorável à preservação, conservação e ao uso racional dos recursos naturais para garantir a sustentabilidade das atividades extrativistas marinhas. Porém, essa percepção entra em contradição diante da necessidade de sobreviver em um lugar onde a renda básica das famílias gira em torno da exploração intensiva da prática extrativista marinha, sendo esta realizada sem o suporte sustentável devido.

A respeito do critério de sustentabilidade ecológica, Sachs (2008) afirma ser possível relacionar com o critério de sustentabilidade ambiental. Esse critério sugere a preservação do potencial capital natural na produção de recursos naturais, e para que exista essa preservação, seria necessária a conscientização dos próprios trabalhadores extrativistas a partir das lideranças locais e instituição responsável. De modo geral, esses dois critérios deveriam servir para estabelecer um aproveitamento racional ecologicamente sustentável dos recursos naturais em favor da população local, unificando o cuidado com a conservação com os interesses da comunidade local, utilizando-se dessa estratégia para a reprodução social das famílias residentes na área.

\section{Considerações finais}

O debate em torno das formas de obtenção dos recursos naturais e o Desenvolvimento Sustentável é amplo e complexo, principalmente no que diz respeito à extração de recursos naturais em áreas protegidas legalmente. A decisão de analisar esse tema levanta inquietações diversas, tanto em relação às formas de apropriação destes recursos quanto às intervenções do Estado (ou sua omissão) enquanto agente regulador. A forma de apropriação da natureza e sua mercantilização em busca do desenvolvimento econômico tornou-se um modelo perverso de destruição dos recursos naturais e de exploração da força de trabalho humana, em que o principal interesse é obter maior lucro sem a compensação dos danos causados, sejam eles socioeconômicos ou ambientais. Segundo Silva (2010), conceber a natureza como totalidade e o gênero humano como elemento consciente implica em construir relações sociais pautadas na negação da exploração.

A partir de experiências vivenciadas no local, análise dos pressupostos teóricos e dados oficiais foi possível corroborar à hipótese inicial do trabalho, onde afirmouse que o modelo econômico definido como sustentável estabelecido nas políticas 
públicas de proteção ambiental para melhorar a qualidade de vida da comunidade de Carnaubeiras e conservar e preservar os recursos naturais locais não têm alcançado os objetivos de sustentabilidade em nenhuma das três dimensões (social, ambiental e econômica).

Os dados coletados acerca das formas de sobre-exploração dos recursos naturais, por meio das atividades extrativistas marinhas desenvolvidas no povoado de Carnaubeiras, levaram a uma questão comum ao sistema produtivo na atualidade: a insustentabilidade do desenvolvimento que está sendo promovido por meio da sobre-exploração, tanto dos recursos naturais como da força de trabalho humano.

A vulnerabilidade dos grupos de extrativistas marinhos destacados nesta pesquisa aponta para aspectos que minimizam ainda mais a qualidade de vida destes trabalhadores em função da força de trabalho empregada para extração dos recursos naturais, que primeiramente deveriam suprir, dentro de uma escala de prioridades, as suas necessidades básicas de alimentação, moradia e saúde. Contudo, a produção extrativista marinha é comercializada por preços ínfimos e insuficientes para obter a mínima qualidade de vida. Estes recursos naturais obtidos por meio do extrativismo marinho tendem, cada vez mais, a tornarem-se escassos diante da busca desenfreada por maior quantidade de produtos disponíveis (caranguejo-uçá, ostra e peixes) para a comercialização. Logo, este ciclo vicioso coloca em cheque a disponibilidade dos recursos naturais para as gerações futuras.

A sustentabilidade socioeconômica e ambiental das atividades produtivas extrativistas marinhas em Carnaubeiras demonstram uma realidade complexa e multifacetada. Isso ocorre em função dos aspectos analisados apontarem para elementos antagônicos: de um lado o modelo de conservação pré-estabelecido e do outro a exploração desmedida da força de trabalho humano e da natureza, contradizendo as intenções conservacionistas na área. No entanto, tais aspectos seguem interligados, presentes na vida cotidiana dessa comunidade tradicional.

Como resultado das pesquisas realizadas, observa-se ainda que a busca pelo desenvolvimento que incorpore a questão ambiental nos processos produtivos e vice-versa é algo ainda distante da realidade vivenciada no povoado. Diante deste cenário sumamente complexo e contraditório, entende-se que algumas atuações seriam cabíveis com o intuito de atenuar o modelo de extrativismo atual. Estas passariam, em primeiro lugar, por uma maior presença do poder público que no local parece omisso das responsabilidades de acompanhamento e fiscalização - a presença do Estado poderia se materializar, por exemplo, mediante um "mercado institucional" que garantisse um preço mínimo justo para os trabalhos realizados pelos pescadores e catadores de caranguejo. Da mesma forma, é pertinente o aprofundamento dos processos de auto-organização por parte da comunidade extrativista marinha, que é atualmente vulnerável, fomentando uma maior 
segurança no trabalho, tornando-o menos penoso, e, ao mesmo tempo, limitaria a ação dos atravessadores.

\section{Referências}

ACSELRAD, Henri. Ambientalização das Lutas - o caso do movimento por justiça ambiental. Estudos Avançados 24, 2010.

BECK, U. O que é Globalização? Equívocos do globalismo: respostas à globalização. São Paulo: Paz e Terra, 1999.

BECKER, H. S. Métodos de Pesquisa em Ciências Sociais. São Paulo: HUCITEC, 1993.

CODEVASF. Industrialização do caranguejo-uçá do Delta do Parnaíba. Brasilia, DF: Codevasf, 2012.

COSTA, P. C. Unidade de Conservação. São Paulo: Aleph, 2002.

DIEGUES, A. C. Pescadores, camponeses e trabalhadores do mar. São Paulo, Ática, 1983.

EMBRAPA. Método reduz perdas com caranguejo-uçá. 2007. Disponível em: http:// www.embrapa.br/imprensa/noticias/2007/outubro/2a-semana/metodoreduz-perdas-com-caranguejo-uca. Acesso em: 20 ago. 2008.

FOLADORI, G. Limites do desenvolvimento Sustentável. Campinas, SP: Imprensa oficial, 2001.

HARDIN, G. The Tragedy of the Commons. Science, New York.v.162, p.1243$1248,1968$.

HART, S. L.; MILSTEIN, M. B. Criando valor sustentável. Academia de Gestão Executiva, 2003.

ICMBIO. Instituto Chico Mendes de Conservação e Biodiversidade. Relatório de Fiscalização - Operação Carcinicultura. Área de Proteção Ambiental Delta do Parnaíba. 40 p. 2009. Disponível em: http://www.icmbio.gov.br/. Acesso em: 8 jun. 2014. 
IBAMA. Instituto Brasileiro do Meio Ambiente e dos Recursos Naturais Renováveis. Relatório do Grupo Permanente de Estudos (GPE) do caranguejouçá, realizado no período de 17 a 20/12/91, em Fortaleza-CE. Coleção Meio Ambiente. Série Estudos-Pesca, Brasília, DF, 1994.

IBAMA. Estatística da Pesca Marítima e Estuarina do Nordeste do Brasil2005.Estapesca, SEAP-PR. CD-ROM. Disponível em meio eletrônico, 2005.

JONES, D. A. Crabsofthe mangal ecosystem. In: Por, F. D. \& I. Dor, eds. Hydrobiology of the Mangal, W. Junk Publishers, The Hague. p. 89-109; 1984.

LEFF, E. Ecologia, capital e cultura: a territorialização da racionalidade ambiental. Petrópolis, RJ: Vozes, 2009.

LIMA, D. Equidade, Desenvolvimento Sustentável e Preservação da Biodiversidade. In: CASTRO, Edna; PINTOS, F. (Eds.). Faces do Trópico Úmido. Belém: Cejup, 1997.

LUSTOSA, A. H. M. Práticas Produtivas e (in) sustentabilidade: os catadores de caranguejo do Delta do Parnaíba. Dissertação (Mestrado em Desenvolvimento e Meio Ambiente). Universidade Federal do Piauí. Teresina, 2005. p.172.

MEIRELLES, V. J. S. Etnobotânica e caracterização da pesca na comunidade Canárias, Reserva Extrativista Marinha do Delta do Parnaíba, Nordeste do Brasil. Dissertação (Mestrado em Desenvolvimento e Meio Ambiente). Universidade Federal do Piauí -UFPI, Teresina, 2012.

MÉSZÁROS, I. Para além do capital. São Paulo, Boitempo, 2002.

MÉSZÁROS, I. O desafio e o fardo do tempo histórico. São Paulo, Boitempo, 2007.

MMA. Zoneamento Ecológico Econômico do Baixo Rio Parnaíba: Subsídios técnicos. Relatório Final. Brasília, 2002.

MOTA, R. I. Método primitivo de transporte do caranguejo-uçá compromete sustentabilidade do estoque. Rev. Bras. Enga. Pesca, São Luiz, v. 2, 2007.

NORDI, N. Os Catadores de caranguejo-uçá (Ucidescordatus) da região de Várzea Nova(PB): uma abordagem ecológica e Social. Tese (Doutorado em Ecologia e Recursos Naturais). Universidade Federal de São Carlos, 1992. p.107. 
POLANYI, K. A Grande Transformação: as origens de nossa época. Rio de Janeiro: Editora Campus, 1944.

PORTELLA, C. G. Avaliação da Qualidade da ostra nativa Crassostreabrasiliana congelada em concha em função da composição química e análise sensorial. Dissertação (Mestrado) - Programa de Pósgraduação em Aquicultura - UNESP, São Paulo, 2005.

RIOS, E. C. Seashells of Brasil. 2.ed. Rio Grande, RS. Editora da fundação Universidade do Rio grande, 1994.

SACHS, I. Espaços, Tempos e Estratégias do Desenvolvimento. Tradução de Luiz Leite de Vasconcelos e Eneida Araujo. São Paulo. Vértice, 1986.

SACHS, I. Estratégias de Transição para o Século XXI: Desenvolvimento e Meio Ambiente. Tradução Magda Lopes. São Paulo. Studio Nobel: Fundação do Desenvolvimento Administrativo, 1993.

SACHS, I. Caminhos para o Desenvolvimento Sustentável. 2. ed. Rio de Janeiro, Garamond, 2002.

SACHS, I. Desenvolvimento? Includente, Sustentável, Sustentado. Rio de Janeiro: Garamond, 2004.

SACHS, I. Caminhos para o Desenvolvimento Sustentável. 3. ed. Rio de Janeiro: Ed. Garamond, 2008.

SALES, R.J.R; MOREIRA, A.C.C.C. Reservas extrativistas no complexo estatutário-lagunar de Iguape e Cananeia-domínio Mata Atlântica, São Paulo; Núcleo de Apoio a Pesquisa sobre Populações humanas e áreas úmidas brasileiras da Universidade de São Paulo. 1996. Série documentos e relatórios de pesquisa.

SEBRAE. Serviço Brasileiro de Apoio às Micro e Pequenas Empresas. Diagnóstico Socioeconômico e produtivo dos catadores de caranguejo de Araioses - MA. São Luís: SEBRAE, 2003.

SILVA, M. G. S. Questão ambiental e desenvolvimento sustentável: um desafio ético-político ao serviço social. São Paulo: Cortez, 2010. 
Endereço para correspondência:

Maria Rodrigues Garcia - mjrodrigues07@hotmail.com

Av. Lourenço Vieira da Silva, 1000, Jardim São Cristovão 65055-310 São Luís/MA, Brasil

Isaac Giribet Bernat-neri54@yahoo.es

Av. Lourenço Vieira da Silva, 1000, Jardim São Cristovão 65055-310 São Luís/MA, Brasil 
Maria Rodrigues Garcia e Isaac Giribet Bernat

78 | Revista Brasileira de Desenvolvimento Regional, Blumenau, 7 (2), P. 51-78, 2019 